\title{
Geospatial analysis of habitat use in yellowtail flounder Limanda ferruginea on Georges Bank
}

\author{
Jose J. Pereira ${ }^{1, *}$, Eric T. Schultz ${ }^{2}$, Peter J. Auster ${ }^{3}$ \\ ${ }^{1}$ NOAA Fisheries, Milford Laboratory, 212 Rogers Avenue, Milford, Connecticut 06460, USA \\ ${ }^{2}$ Dept. of Ecology and Evolutionary Biology, University of Connecticut, Storrs, Connecticut 06269-3043, USA \\ ${ }^{3}$ Department of Marine Sciences at the University of Connecticut, and Sea Research Foundation-Mystic Aquarium, \\ Groton, Connecticut 06340, USA
}

\begin{abstract}
Three theories of habitat use proposed for marine fishes - the constant density model, the proportional density model, and the basin model-make contrasting predictions of how the geographical range, local density, and fitness change as population size changes. We tested model predictions with survey data on yellowtail flounder Limanda ferruginea from the Georges Bank region, where abundance changed by a factor of 4 over a decade. Surveys took place in spring and fall, and data on individual length, mass, sex, and reproductive status were available. Analysis of spatial pattern revealed that the overall area occupied by flounder increased by a factor of 2 when abundance was high, and local density increased predominantly in high quality habitat that had been closed to commercial fishing. Condition, which served as a proxy for fitness, was lower in females when abundance was high. Geospatial analysis revealed mesoscale variability in condition, over $10 \mathrm{~s}$ to $>100 \mathrm{~km}$, except in the spring season during low abundance periods. Spatial autocorrelation explained as much as $25 \%$ of the variability in condition, indicating that site dependence was a factor in explaining the spatial distribution that we observed. These results are most supportive of both the constant density model and the basin model. This approach detected an important population center for yellowtail flounder and determined its extent using only measures of abundance, location, and condition of individual fish, data commonly collected during routine fishery assessment surveys. Here we demonstrate that analyses linking population responses to variation in such measures at local spatial scales can have significant implications for identifying areas of important fish habitat and suggest greater use of geospatial approaches in conservation and management of exploited species.
\end{abstract}

KEY WORDS: Spatial autocorrelation · Kriging $\cdot$ Yellowtail flounder $\cdot$ Georges Bank $\cdot$ Habitat Resale or republication not permitted without written consent of the publisher

\section{INTRODUCTION}

The processes that shape species distribution are fundamental concerns of ecology and must be taken into account for effective conservation and management strategies. This is especially important for marine fishes, as patterns of exploitation add a major source of variability (Grand \& Grant 1994, Essington \& Kitchell 1999, Abrams 2000). Managing stocks to ensure sustainability may require identification and protection of the highest quality habitat, which pro- duces the highest possible biomass. In particular, closed areas designed to conserve spawning populations of fish are especially effective if located in high quality habitats which are always occupied by spawning adults regardless of whether overall population levels are high or low.

Differential patterns of survival and active habitat selection, separately or together, result in the patchy distributions of fishes that we observe. The conceptual definition of habitat, the area where an animal lives (Smith \& Smith 1998), is intuitive and straight- 
forward. The operational definitions used to define this area, however, are many and varied. Presence/ absence of a species, niche description and quantification (Pittman \& McAlpine 2003), variation in distribution of fish communities (Auster et al. 2001), and variation in population density (Knight \& Morris 1996) have all been used to identify habitat. However, individuals are often found in suboptimal habitats, and the mere presence of an organism in a particular habitat does not indicate that the population can sustain itself there (Schultz \& Ludwig 2005). Ecological sinks (Pulliam 1988, Pulliam \& Danielson 1991, Delibes et al. 2001) and traps (Kristan III 2003) can promote population of poor habitats. Hence, incorporating some measure of habitat quality into our habitat definitions can contribute to the conservation and sustainability of exploited species such as marine fish. An individual in high quality habitat enjoys high energy intake and/or low risk of predation or disease and therefore has high rates of survival and reproduction. Energy not used in compensating for adverse abiotic factors (temperature, salinity, dissolved oxygen, current) can also be diverted into growth or reproduction. We refer generally to this as a fitness benefit.

Three theoretical constructs have been used to explain the relationship between abundance and distribution in marine fishes: the constant density model (CDM), the proportional density model (PDM), and the basin model (BM) (Petitgas 1998). The CDM predicts that local density remains constant and the range (the total area occupied by the species) expands and contracts with changes in global abundance (Iles \& Sinclair 1982, Hilborn \& Walters 1992). The mechanism driving the CDM could be territoriality (Hilborn \& Walters 1992) or, more generally, site dependence (Rodenhouse et al. 1997). Individuals claim exclusive access to some site (portion of habitat), and their presence precludes use by other individuals. Habitat quality does not degrade with occupation of adjacent areas, and more habitat is occupied as the population grows (Rodenhouse et al. 1997). Individual reproductive success is determined in part by habitat quality and is unaffected by population size (McPeek et al. 2001). The CDM, driven by site-dependence, predicts that fitness is greater in higher quality habitat that is occupied first (Rodenhouse et al. 1997). Territoriality can be seen as a special case of site dependence in which dominant individuals actively exclude subordinates, but individual reproductive success is still determined by habitat quality. This is also equivalent to the ideal dominance model proposed by Fretwell \& Lucas (1969).
The PDM predicts that range remains constant and local density changes proportionally with changes in global abundance (Houghton 1987, Myers \& Stokes 1989, Hilborn \& Walters 1992, Petitgas 1998). The PDM was used to explain North Sea haddock and American plaice distributions on the Grand Banks of Newfoundland (Myers \& Stokes 1989), but no mechanism was proposed to account for it. Local processes that provide enhanced prey resources could result in increases in local density in phase with changes in global population (Petitgas 1998). Spatial heterogeneity in post-settlement survival due to availability of predator refuges (Levin 1994) would also provide an ecological mechanism for proportional changes in local abundance in the context of site-dependent habitat use. As originally described, the PDM made no predictions regarding fitness, but if a site-dependent mechanism is the basis for the PDM as discussed above, then differences in fitness should be detectable among habitats as in the CDM.

The BM predicts that both local density and species range change with changes in global abundance (MacCall 1990) and proposes density-dependent habitat use (Fretwell \& Lucas 1969) as the mechanism. Fretwell \& Lucas (1969) theorized that habitat choice is influenced by habitat suitability, now commonly interpreted as the fitness value. The fitness value is also inversely related to population density. Hence, habitat use is density dependent, and an optimizing individual will leave initially high quality habitat when high abundance there has depressed fitness below that which can be obtained in a lower quality but less crowded habitat. Fretwell \& Lucas (1969) referred to this scenario as ideal free distribution. MacCall (1990) incorporated these ideas in his BM, using habitat choice as the driving force behind changes in local population density, global abundance, and the range occupied by a species. Simpson \& Walsh (2004) concluded that yellowtail flounder Limanda ferruginea distributions were consistent with the BM because the range changed with changes in population size; however, they lacked an estimate of fitness, and their results could also be consistent with the CDM. In order to distinguish between the BM and the CDM one needs to look at local population density and some measure of fitness. While the BM predicts that fitness should be the same across habitats, the CDM, if driven by sitedependent habitat use, predicts that higher quality sites will produce individuals with higher fitness. For this reason, Shepherd \& Litvak (2004) recommend incorporating analyses of spatial variation in fitness in tests of density-dependent habitat use. 
Linking the demographics of managed species to particular models of habitat use can have important implications for development and testing of management strategies. The growth potential of a population will depend on whether the spawning stock is distributed in a way that homogenizes fitness, or alternatively is distributed into sources and sinks. The need for and potential boundaries of areas to protect juveniles or spawning adults in a population will depend on species-specific responses to variation in population size. Further, understanding and interpreting responses to habitat management actions will also depend on model fit. A decrease in fitness across a population (e.g. observed as a decrease in growth or fecundity) may be interpreted as a failure of a conservation scheme, but this is the expected response with an increase in abundance for species that fit the BM.

The objectives of this study were to test predictions made by these 3 models of habitat use (summarized in Table 1) with data from portions of a $48 \mathrm{yr}$ long time series on yellowtail flounder Limanda ferruginea on Georges Bank (NW Atlantic). These data permitted tests of habitat selection theories on a large spatial scale. We determined if geographical range increases and local population density remains constant, or if ranges and density both change, when a low abundance period is compared to a high abundance period. We tested for spatial variation in proxies of fitness as suggested by Shepherd \& Litvak (2004), and determined whether fitness is site driven or related to population size.

\section{METHODS}

The National Marine Fisheries Service has conducted a biannual bottom trawl survey of the northeast continental shelf since 1963 in order to assess the abundance of economically important marine species (Grosslein 1969). The survey covers the continental shelf from Cape Hatteras, North Carolina, northward into Canadian waters (Fig. 1). Sampling stations are chosen randomly each year within strata that are defined by depth and temperature. The number of stations are proportional to stratum area (Grosslein 1969, Azarovitz 1981), with the

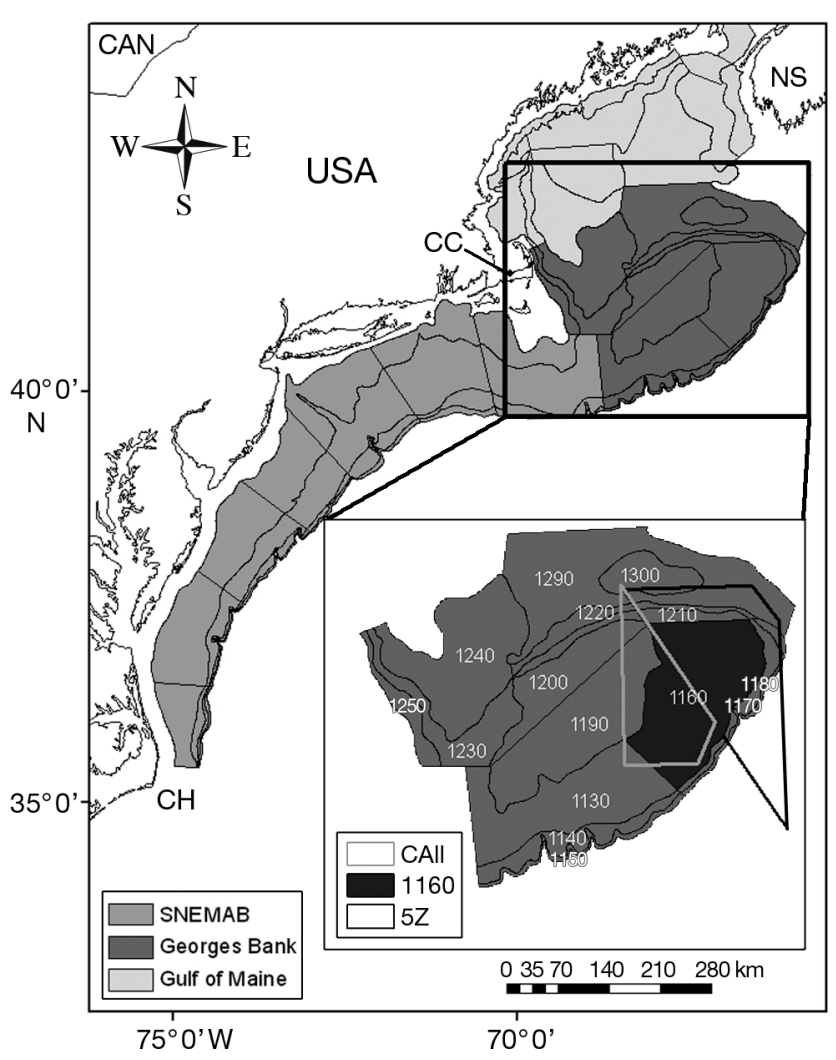

Fig. 1. Limanda ferruginea. Yellowtail flounder stocks. The area off the northeast coast of the United States surveyed by the National Marine Fisheries Service showing sampling strata (indicated by contour lines) and management areas the Gulf of Maine, Georges Bank, and the southern New England-Middle Atlantic Bight (SNEMAB). Inset shows Georges Bank, Stratum 1160, Closed Area II (CAII), and Statistical Zone 5Z. NS, CAN: Nova Scotia, Canada. CC: Cape Cod, CH: Cape Hatteras

Table 1. Limanda ferruginea. Model predictions of changes in distribution and fitness with population size (N). Geographical range is the total area occupied by the species. Local density is the catch per unit effort within a given area. Local fitness is a measure of fish health generated from length and weight of individual fishes within a given area. Spatiotemporal variation in fitness is the predicted reaction of the fitness metric to changes in population size. CDM: constant density model; PDM: proportional density model; BM: basin model

\begin{tabular}{|lllll|}
\hline Model & Geographical range & Local density & Local fitness & Spatiotemporal variation in fitness \\
\hline CDM & Increases with N & Constant over N & Constant over N & Spatial variance at high N \\
PDM & Constant over N & Constant proportion of N & Constant over N & Spatial variance at high N \\
BM & Increases with N & Increases with N ${ }^{a}$ & Decreases with N & No change in spatial variance with N \\
aThe increase may be more pronounced if fish follow a Beverton-Holt stock-recruitment relationship
\end{tabular}


exception of shallow central areas of Georges Bank; the minimum number of stations in a stratum is 2 . Between 350 and 400 stations are typically sampled on a survey, approximately 1 for each 200 square nautical miles.

Trawls are conducted in a standardized fashion. Details of the trawl survey design in addition to this summary can be found in Reid et al. (1999). A net is towed by the survey vessel for $30 \mathrm{~min}$, during which the ship covers about 1.5 nautical miles. For each tow, environmental data (water temperature, depth, salinity) are collected, and the catches are sorted by species, counted, and a subsample is weighed and measured. Catch per unit effort (CPUE) is estimated as catch per tow. The area swept by the net appears to be consistent based on calculations made during the 2006 season. The mean area swept was $0.74 \mathrm{~km}^{2}$, and the standard deviation was $0.0007 \mathrm{~km}^{2}$, assuming that door spread is constant at the mean value of $22.15 \pm 0.21 \mathrm{~m}$.

We chose to use yellowtail flounder Limanda ferruginea for our geospatial tests of habitat models because it has exhibited wide variation in population size (Fig. 2). Low (1992 to 1995) and high (1999 to 2004) abundance periods were selected based on stock assessments (NEFSC 2008). This species is managed as 3 sub-populations: Cape Cod to Gulf of Maine, Georges Bank, and the southern New England-Middle Atlantic Bight (Fig. 1). We focused on the Georges Bank stock because yellowtail flounder are most numerous there. Some areas of Georges Bank have been closed to commercial fishing as part of fisheries management plans. Closed Area II (CAII)

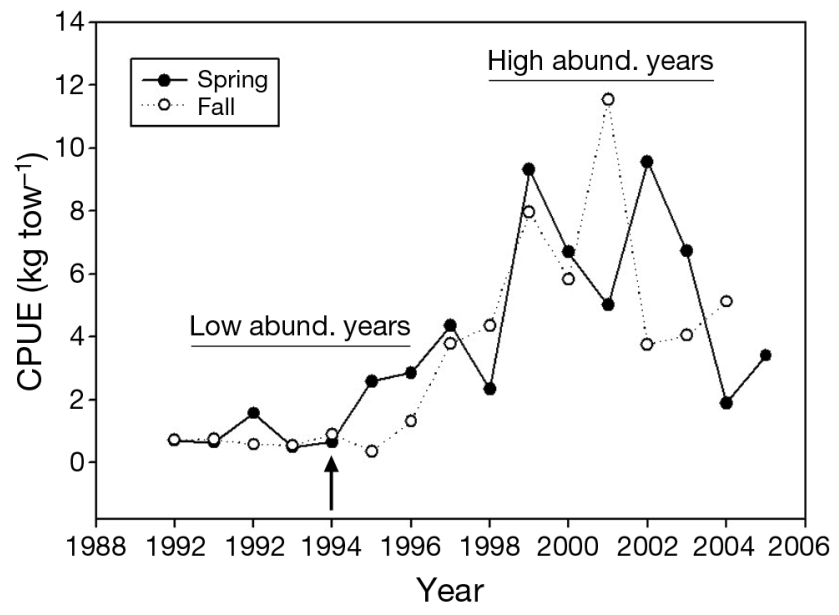

Fig. 2. Limanda ferruginea. Relative abundance of yellowtail flounder on Georges Bank from 1990 to 2005 in the spring and in the fall (data from NEFSC 2008). Arrow indicates the beginning of closures of Areas CAII and 5Z in 1994 (see 'Methods'). CPUE: catch per unit effort was closed by the United States in 1994 (Fig. 1). The area has been open on a limited-access basis since 1999 for harvest of sea scallops Placopecten magellanicus, with restrictive controls to minimize bycatch of yellowtail flounder. Canada closed parts of Area $5 Z$ (Fig. 1) to groundfish harvest from January to May from 1994 through 2004. Georges Bank trawl survey CPUE was higher by a factor of 4 during the high abundance period.

To test predictions regarding the effect of abundance on geographical range, individual catch records were plotted using a geographic coordinate system (North American Datum of 1983 [NAD 1983]) using the latitude and longitude where each trawl began. Coordinates were then reprojected into Universal Transverse Mercator (UTM, Zone 19N; NAD 1983) system to permit accurate measurements of distances, geospatial relationships, and areas occupied. Geographical range (i.e. total area occupied) at high and low abundance periods was quantified using a kernel density estimator. The kernel density estimator calculates fish density within a circular surface around a point based on a selected search radius and the number of fish caught there. The result is displayed as a raster coverage. We used an a priori value of $20 \mathrm{~km}$ for our search radius, based on known yellowtail migration distances from tagging studies (Stone \& Nelson 2003). The output raster data were converted to polygons so that the area could be calculated (ArcGIS 9.3.1, 10.0). Differences in mean areas occupied during high versus low abundance periods were tested via a 2 -sample $t$-test.

To test predictions regarding local density, we compared localized population densities within high quality habitat to those on Georges Bank as a whole. Stratum 1160 (Fig. 1) is assumed to be high quality habitat based on the consistently high numbers of yellowtail flounder found there. Yellowtail flounder eggs, larvae, juveniles, and adults are all found in this area (Johnson et al. 1999); it has the sandy substrate (Almeida et al. 2005, Kostylev et al. 2005, Link et al. 2005) and food items that yellowtails prefer (Johnson et al. 1999, Link et al. 2002). Tagging studies also indicate limited movements of yellowtails out of this area (Stone \& Nelson 2003). The total survey catch from Stratum 1160 for each year was expressed as a percentage of the catch from Georges Bank as a whole, and the relationship between the catch in Stratum 1160 and the total catch on Georges Bank was tested via regression. We also compared CPUE within Stratum 1160 to that on the rest of Georges Bank.

We tested predictions regarding spatial heterogeneity in fitness using a condition index expressing 
relative fish mass. Individual fish masses and lengths have been recorded in trawl surveys beginning in 1992. The relationship between mass and length in fishes has long been used in various forms as a measure of health or condition (Le Cren 1951), and is an indicator of energy available for reproduction (Burton \& Idler 1984, Burton 1994). We used the residual mass index described in Jakob et al. (1996): we estimated the predictive mass-length relationship via log-log regression (Fig. 3) and determined each individual's deviation from the regression. Prior to estimating each individual's residual mass index, the mass-length data were subdivided into groups based on season, sex, and gonadal development. Lengthweight relationships are likely to be different in spring and fall because of gonadal development during the spawning season. Mature ovaries can comprise $20 \%$ or more of a female yellowtail flounder's mass (Wilk et al. 1990), so fish of the most frequently occurring maturity stage were used for the analysis for each season to minimize these differences. The maturity classification scheme used was that first proposed by Morse (1979). Each fish was classified upon capture as immature (I), developing (D), ripe $(\mathrm{R})$, spent $(\mathrm{S})$, resting $(\mathrm{T})$, or unknown $(\mathrm{X})$. Yellowtail flounder spawn in the spring; most of the fish captured during the fall survey were in Class $\mathrm{T}$, while most of the fish during the spring survey were in Class D.

To test the predictions regarding fitness, we analyzed variability in condition in 2 spatial domains. We conducted an among-stratum analysis via a nested mixed-model analysis of variance (ANOVA). The main effects in this model were abundance (2 levels:

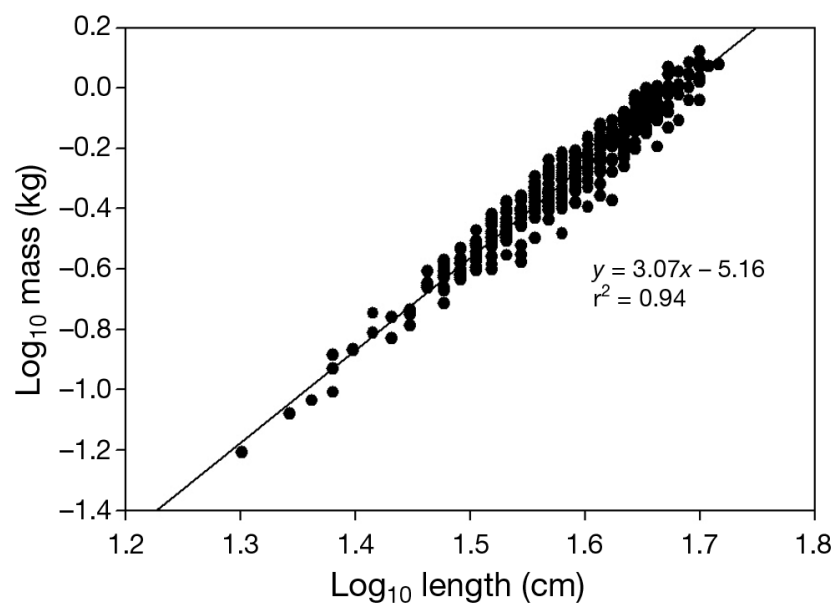

Fig. 3. Limanda ferruginea. Log-log regression of mass and length from fall-caught female yellowtail flounder. Deviation from regression (details indicated) is used as a measure for individual condition low and high), stratum (11 levels), season (fall and spring), and year (random effect nested within each combination of abundance, stratum, and season). The analysis was conducted separately for each sex. We used the MS (error) of the nested effect in the denominator for $F$-tests of each interaction and main effect. We conducted a mesoscale (10s to 100 s of kilometers) analysis via geospatial tools for assessing spatial autocorrelation. This analysis was conducted separately on each combination of sex, season, and abundance. We constructed a prediction surface using kriging or cokriging (see Appendix 1). To determine whether there was significant spatial autocorrelation in condition, we regressed observed values of condition against the expected values estimated by kriging, referred to henceforth as $\widehat{\mathrm{k}}$. A statistically significant regression was taken as evidence of spatial autocorrelation in condition. Because there is the potential for confounding spatial and temporal effects in these multi-year datasets, we tested for combined effects of year and $\hat{\mathrm{k}}$ on observed values of condition in analyses of covariance (ANCOVAs). We also tested for a year effect on $\widehat{k}$ in 1 -way ANOVAs. Year was included as a categorical variable in each analysis.

\section{RESULTS}

Yellowtail flounder Limanda ferruginea occupied larger geographic ranges during the high abundance period (Table 2). The areas occupied were significantly greater during the high abundance period in both the spring $(p=0.03)$ and the fall $(p=0.002)$. In both seasons, the mean area occupied increased from about 4000 to about $8000 \mathrm{~km}^{2}$.

Over time, local population density in high quality habitat (Stratum 1160) increased more quickly than on the rest of Georges Bank and was an increasingly larger percentage of the total survey catch (Fig. 4). In the early 1970 s about $30 \%$ of the survey's catch of yellowtail flounder was captured

Table 2. Limanda ferruginea. Geographical range of yellowtail flounder on Georges Bank. Differences in mean areas occupied during low and high abundance periods were significant $(p<0.05)$ for both fall and spring

\begin{tabular}{|c|c|c|c|}
\hline Season & $\begin{array}{l}\text { Area } \\
\text { Low period }\end{array}$ & $\begin{array}{l}\left(\mathrm{km}^{2}\right) \\
\text { High period }\end{array}$ & $\mathrm{p}$ \\
\hline Fall & 3966 & 8676 & 0.002 \\
\hline Spring & 3844 & 7907 & 0.03 \\
\hline
\end{tabular}




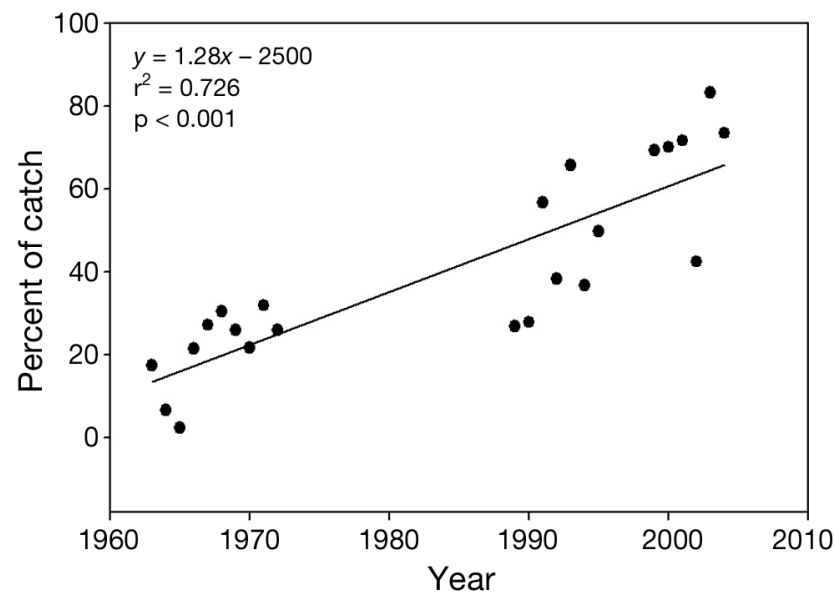

Fig. 4. Limanda ferruginea. Proportional abundance of yellowtail flounder in preferred habitat (Stratum 1160, see Fig. 1). Abundance is expressed as a percentage of the total survey catch on Georges Bank. Equation for least-squares regression, correlation coefficient, and p-value are indicated

from Stratum 1160. By 2004 it had risen to nearly $70 \%$ of the Georges Bank sample (Fig. 4) and was an order of magnitude higher than CPUE elsewhere (Fig. 5). The geographical distribution of the population is shown in Fig. 6.

Condition indices for females were significantly lower when populations were high but not for males

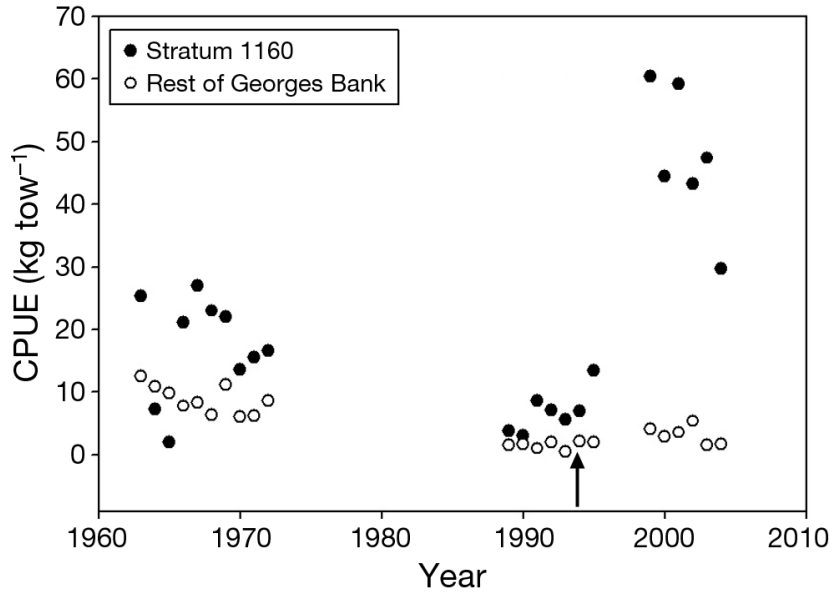

Fig. 5. Limanda ferruginea. Comparative density (as catch per unit effort, CPUE) of yellowtail flounder in high quality habitat (Stratum 1160, see Fig. 1) and elsewhere on Georges Bank by year. Arrow indicates the beginning of closures of Areas CAII and 5Z in 1994 (see 'Methods')

although they trended in that direction (Fig. 7). Males had significantly lower condition indices in the spring when compared to the fall (Table 3). The significant stratum result in the males was due to a difference between 2 strata, 1170 and 1200 (Fig. 1). Year nested within abundance period, season, and stratum was significantly different for both males and
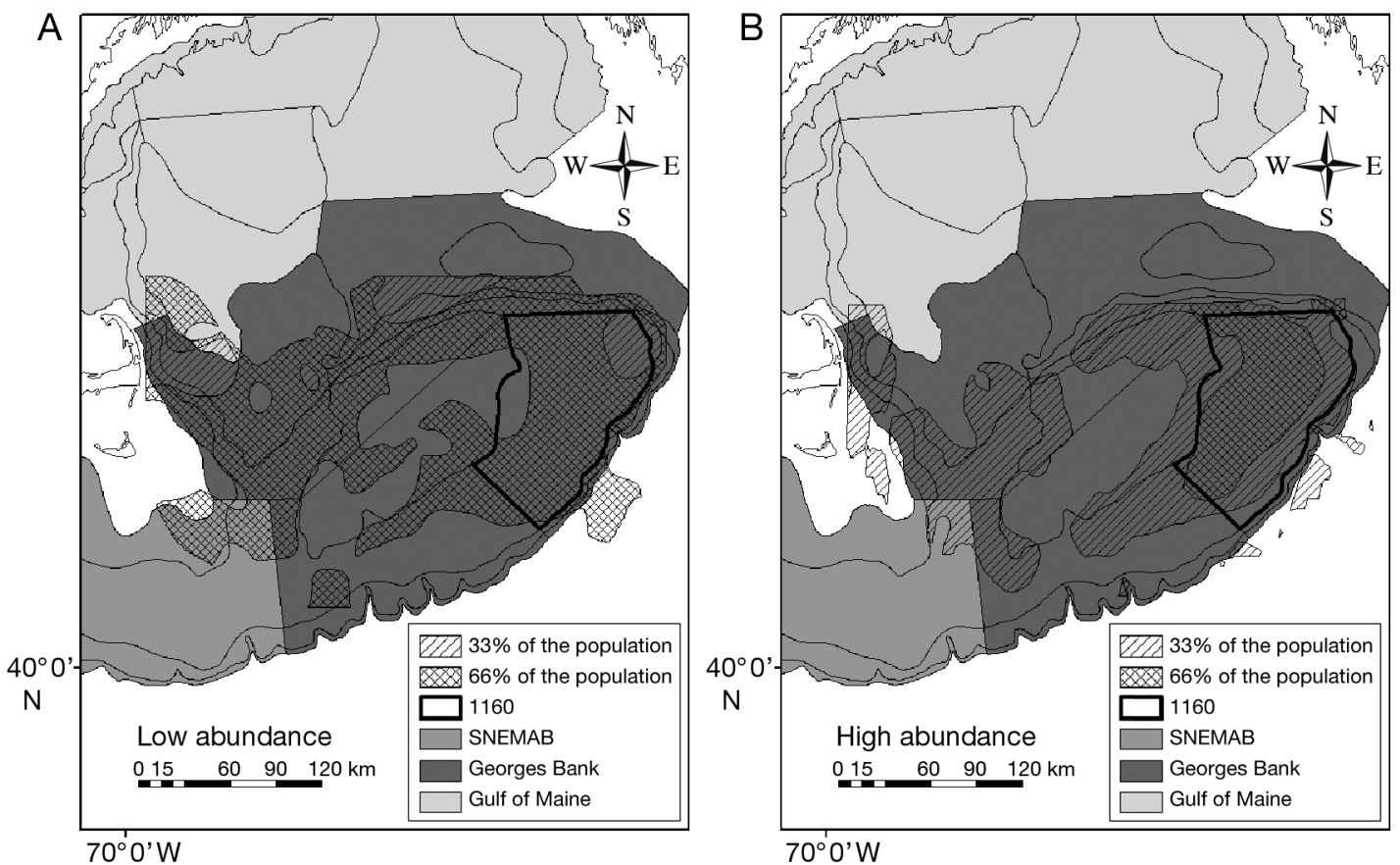

Fig. 6. Limanda ferruginea. Distribution of yellowtail flounder population on Georges Bank during (A) low and (B) high abundance. The cross-hatched area represents the area within which approximately $66 \%$ of the population resided. The hatched area represents the distribution of an additional $33 \%$ of the population. Together they account for $99 \%$ of the area occupied by the population. For area details see Fig. 1 
Table 3. Limanda ferruginea. Test of spatial and temporal variability in condition. Results of mixed-model ANOVA, testing each sex separately. Abundance: abundance period. When the degrees of freedom (df) for an effect differed between males and females they were both listed (as males, females). MS: Type III mean squares. $F$ and p-values given for the null hypothesis that there is no effect. Significant $p$ values $(\leq 0.05)$ in bold

\begin{tabular}{|c|c|c|c|c|c|c|c|}
\hline & \multirow[t]{2}{*}{$\mathrm{df}$} & \multicolumn{3}{|c|}{-Males } & \multicolumn{3}{|c|}{-Females } \\
\hline & & MS & F & $\mathrm{p}$ & MS & $F$ & $\mathrm{p}$ \\
\hline Abundance (a) & 1 & 0.0043 & 1.13 & 0.29 & 0.044 & 6.3 & 0.01 \\
\hline Stratum (s) & 9 & 0.068 & 2.0 & 0.05 & 0.0038 & 0.6 & 0.79 \\
\hline Season (e) & 1 & 0.032 & 8.41 & 0.005 & 0.002 & 0.26 & 0.61 \\
\hline $\mathrm{a} \times \mathrm{s}$ & 8 & 0.032 & 1.06 & 0.4 & 0.02 & 0.36 & 0.94 \\
\hline $\mathrm{a} \times \mathrm{e}$ & 1 & 0.0003 & 0.08 & 0.8 & 0.004 & 0.55 & 0.46 \\
\hline $\mathrm{s} \times \mathrm{e}$ & 9 & 0.049 & 1.43 & 0.19 & 0.02 & 0.35 & 0.94 \\
\hline $\mathrm{a} \times \mathrm{s} \times \mathrm{e}$ & 5 & 0.0226 & 1.2 & 0.32 & 0.0013 & 0.21 & 1.0 \\
\hline $\operatorname{Year}(\mathrm{a} \times \mathrm{s} \times \mathrm{e})$ & 76,84 & 0.287 & 2.69 & $<0.0001$ & 0.6 & 3.5 & $<0.0001$ \\
\hline Error & 950,921 & 0.0014 & & & 0.002 & & \\
\hline
\end{tabular}

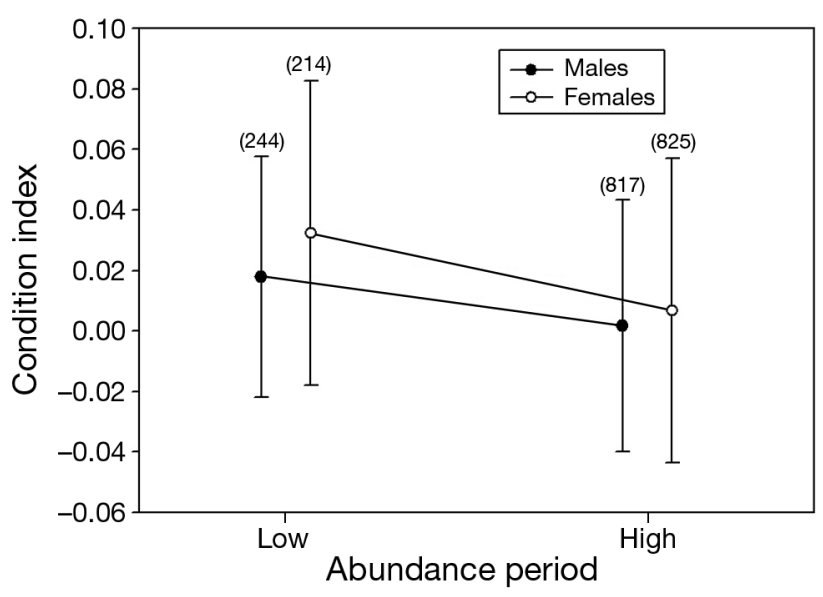

Fig. 7. Limanda ferruginea. Mean $( \pm \mathrm{SD})$ condition indices for yellowtail flounder during low and high abundance periods, fall and spring data combined. Sample size in parentheses. The difference is significant for females, but not for males

females (Table 3). Mean condition indices were mostly positive despite the fact that they were based on residuals because we selected the most common reproductive stages during the spring and fall surveys to minimize differences due to spawning condition. Fish that were categorized as recently spawned or spent (S) were more likely to show a negative condition index than the stages most common during the surveys, namely resting $(\mathrm{T})$ for the fall and developing (D) in the spring.

Geospatial analysis suggested that there was mesoscale variability in condition, some but not all of which was due to confounding of spatial and temporal effects. Outliers identified by robust regression showed no consistent pattern with regard to location, temperature, salinity, or depth. In the fall, during both low and high abundance periods, the cross-validation slope of observed condition versus predicted values from $\widehat{\mathrm{k}}$ was significant, and 15 to $>25 \%$ of the variability in condition was due to spatial effects (Table 4). In the spring, when abundance was low, condition was not spatially autocorrelated, but, during the high abundance period, condition was again spatially autocorrelated, explaining 9 to $>25 \%$ of the variance. The ACD, the maximum distance at which condition was spatially autocorrelated, differed with abundance for each sex/season combination save 2 (Table 4). The ACD was comparable for males and females during the high abundance period (roughly $80 \mathrm{~km}$ during the fall season and 30 to $40 \mathrm{~km}$ during the spring). It was larger during the low abundance period among males in the fall and females in the spring. The level of variability in condition among samples outside of the influence of spatial autocorrelation (partial sill) was typically lower during high population periods than for low population periods. To tease out the effect of among-year variability in condition in the geospatial analysis, we tested for combined effects of year and $\widehat{\mathrm{k}}$ in ANCOVAs and the effect of year alone in ANOVAs (Table 5). When year

Table 4. Limanda ferruginea. Geospatial test statistics for variability of condition, for each combination of season, sex, and abundance period from the semivariogram. N: sample size; slope: cross-validation regression slope of the relationship between each observed value and the expected value estimated by kriging $(\widehat{k})$ while deleting the observed value; $\mathrm{R}^{2}$ : measure of the regression's goodness of fit; ACD: autocorrelation distance (see Appendix 1); partial sill: semivariance between points that are sufficiently far apart to be uncorrelated. ${ }^{* *}$ Significant at $\mathrm{p}<0.01$, under nullhypothesis that the slope is 0

\begin{tabular}{|lllcccc|}
\hline & $\begin{array}{c}\text { Abund. } \\
\text { period }\end{array}$ & $\mathrm{N}$ & Slope & $\mathrm{R}^{2}$ & $\begin{array}{c}\text { ACD } \\
(\mathrm{km})\end{array}$ & $\begin{array}{c}\text { Partial } \\
\text { sill }\end{array}$ \\
\hline Fall & & & & & & \\
Female & Low & 114 & $0.131^{* *}$ & 0.148 & 7.6 & 0.00261 \\
& High & 414 & $0.92^{* *}$ & 0.261 & 80 & 0.000712 \\
Male & Low & 121 & $0.895^{* *}$ & 0.174 & 215 & 0.000236 \\
& High & 301 & $1.13^{* *}$ & 0.225 & 76 & -0.0779 \\
Spring & & & & & & \\
Female & Low & 101 & -0.658 & 0.018 & 125 & 0 \\
& High & 411 & $1.21^{* *}$ & 0.259 & 38.5 & 0.000762 \\
Male & Low & 126 & 0.546 & 0.025 & 0.065 & 0.000348 \\
& High & 516 & $1.05^{* *}$ & 0.086 & 29.9 & 0.00007 \\
\hline
\end{tabular}


and $\hat{\mathrm{k}}$ were both included in ANCOVAs, the effect of $\widehat{\mathrm{k}}$ was significant in all cases except in the spring season during low abundance periods, as described above; the effect of year was typically not significant, except among males sampled in the fall season during the high abundance period. The interaction between year and $\hat{\mathrm{k}}$ was significant in 1 dataset. When year alone was included in ANOVA, it was significant in 5 datasets, i.e. it took up some of the variance that had been represented by $\hat{k}$ in the ANCOVA. However, the variance explained by year alone was not as great as the variance explained by $\hat{\mathrm{k}}$ alone: $\mathrm{R}^{2}$ values in Table 5 are less than $\mathrm{R}^{2}$ values in Table 4 , with 2 exceptions, males and females during low population periods in the spring. When we investigated the effect of stratum and season on the condition indices of males, the $\mathrm{R}^{2}$ values from the ANOVA for stratum (0.025) was equivalent to the $\mathrm{R}^{2}$ value of the non-significant regression for males in the spring during the low population period (Table 4). The $\mathrm{R}^{2}$ value for season (0.001) was lower than all other values in Table 4.

\section{DISCUSSION}

We found the strongest support for the BM, some responses that were consistent with the CDM and no support for the PDM. As abundance increased, geographical range increased (supporting $\mathrm{CDM}$ and $\mathrm{BM})$, local density increased (supporting BM), and average fitness decreased (at least in females), supporting the BM. Condition, our metric of fitness, was spatially autocorrelated (supporting CDM) in 6 of 8

Table 5. Limanda ferruginea. Effect of interannual differences in condition on geospatial analysis, for each combination of season, sex, and abundance period (low or high). P-values: for effect of categorical variable year ( $\mathrm{p}[\mathrm{yr}])$, continous variable $\widehat{\mathrm{k}}(\mathrm{p}[\widehat{\mathrm{k}}])$, with $\widehat{\mathrm{k}}$ being the expected value of condition, and their interaction $\mathrm{p}[\mathrm{yr} \times \hat{\mathrm{k}}])$. Significant $\mathrm{p}$-values in bold

\begin{tabular}{|c|c|c|c|c|c|c|}
\hline & \multirow{2}{*}{$\begin{array}{l}\text { Abund. } \\
\text { period }\end{array}$} & \multirow{2}{*}{$\mathrm{p}(\mathrm{yr})$} & \multirow{2}{*}{\multicolumn{2}{|c|}{$\begin{array}{l}\text {-ANCOVA } \\
\quad \mathrm{p}(\widehat{\mathrm{k}}) \mathrm{p}(\mathrm{yr} \times \widehat{\mathrm{k}})\end{array}$}} & \multicolumn{2}{|c|}{ ANOVA } \\
\hline & & & & & $\mathrm{p}(\mathrm{yr})$ & $\mathrm{R}^{2}$ \\
\hline \multicolumn{7}{|l|}{ Fall } \\
\hline \multirow[t]{2}{*}{ Female } & Low & 0.48 & 0.0004 & 0.33 & 0.11 & 0.053 \\
\hline & High & 0.46 & $<0.0001$ & 0.36 & 0.18 & 0.019 \\
\hline \multirow[t]{2}{*}{ Male } & Low & 0.63 & 0.0043 & 0.80 & 0.0074 & 0.097 \\
\hline & High & 0.0002 & $<0.0001$ & 0.41 & $<0.0001$ & 0.13 \\
\hline \multicolumn{7}{|l|}{ Spring } \\
\hline \multirow[t]{2}{*}{ Female } & Low & 0.49 & 0.55 & 0.28 & 0.0044 & 0.13 \\
\hline & High & 0.13 & 0.0003 & 0.079 & $<0.0001$ & 0.23 \\
\hline \multirow[t]{2}{*}{ Male } & Low & 0.27 & 0.81 & 0.023 & 0.31 & 0.029 \\
\hline & High & 0.06 & $<0.0001$ & 0.26 & $<0.0001$ & 0.082 \\
\hline
\end{tabular}

sex/abundance/season combinations we examined (Table 5).

Geographical range occupied by yellowtail flounder Limanda ferruginea on Georges Bank doubled from $\sim 4000$ to around $\sim 8000 \mathrm{~km}^{2}$ (Table 2) when abundance increased. Yellowtail flounder in Canadian waters on the Grand Bank showed a similar response (Brodie et al. 1998, Simpson \& Walsh 2004). Both the CDM and BM predict this change; the PDM predicts that geographic range is constant and does not change with abundance.

Local density within preferred habitat (Stratum 1160) increased over time. This result (Fig. 5) supports the BM over the CDM, which predicts constant density within preferred habitat. Moreover, density in preferred habitat increased disproportionally (Fig. 4), contradicting the PDM. Barange et al. (2009) noted similar results for multiple anchovy and sardine populations in various locations. Local population density (similar to our results here) also increased when abundance increased. The BM predicts this disproportionate increase in density if the relationship between spawners and recruits follows a Beverton-Holt type relationship (MacCall 1990). Both Cushing (1973) and Shepherd (1982) agree that a Beverton-Holt stock-recruitment curve is expected for most flatfish. Brodziak \& Legault (2005) have demonstrated that a BevertonHolt type response is a good fit for yellowtail flounder. The proportion of the survey catch in Stratum 1160 between 1999 and 2004 continues to increase (Fig. 4) even as the abundance for Georges Bank peaks and then begins to decline (Fig. 2). This may be due to continued recovery of the habitat and the lack of fishing activity and is in keeping with the Beverton-Holt stock-recruitment response.

Condition in females was lower during periods of higher abundance (Table 3, Fig. 7), which also is consistent with the BM. The CDM and PDM predict that condition at a given site should remain invariant with changes in abundance, because fitness is determined by site and not population size. Condition indices in males were not significantly different when high and low abundance periods were compared (Table 3, Fig. 7). Male energy requirements are lower than for females, especially during spawning season, and they were probably able to find enough food even though population size was larger and there was more competition for food.

The increase in abundance occurring over the time period we selected (Fig. 2) was due in large part to the closures of CAII and 5Z, which almost completely 
contain the region we regard as preferred habitat (Stratum 1160). Abundance was relatively high in Stratum 1160 prior to the closures (Fig. 5); parts of Stratum 1160 had been dubbed the 'Yellowtail Hole' by commercial fishers (Stone \& Nelson 2003). By eliminating commercial fishing, the closures reduced mortality in preferred habitat and probably increased it elsewhere through redirection of fishing effort. Fig. 5 shows that abundance increased within preferred habitat after the closure, while it stayed the same or decreased on the rest of Georges Bank. In addition to reducing the mortality rate of recruited classes of fish, the cessation of fishing also has a direct effect on habitat quality. Fishing activity impacts habitat (Auster et al. 1996, Auster \& Langton 1999), which may recover upon cessation of fishing (Lindholm et al. 2004, Kaiser et al. 2006, Asch \& Collie 2008). The rapid increase in local abundance and the recovery of the habitat (an increase in carrying capacity) may be a unique response following establishment of closed areas and may explain results supporting the CDM. MacCall (1990) predicts that the rapid increase in population density of fish under a Beverton-Holt, spawner-recruit relationship would not be accompanied by an increase in area occupied. The improving habitat and the rapid increase in local density may in fact mimic a site-dependent response.

Geospatial analysis revealed considerable mesoscale variability in condition at most times (Table 4). According to the predictions in Table 1 this result supports the CDM versus the BM, which predicts that condition should be the same across habitats. It could also be the result of a Beverton-Holt spawnerrecruit response along with the area closures as we have noted before. The ACDs shown in Table 4 for males and females during high abundance in the fall are similar ( $80 \mathrm{vs} .76 \mathrm{~km}$ ) as are those in the spring (38.5 vs. $29.9 \mathrm{~km}$ ). These distances probably reflect the 2 habitats identified in the closed area. The ACD may be larger in the fall because food is more abundant over a larger area at this time of year or because the fish have begun their fall migration. The large discrepancy in range between males and females during low population periods in the fall probably reflects the effect of stratum on fitness of males (Table 3) arising from the difference in habitat quality between Strata 1170 and 1200 (Fig. 1).

Spatial variability in condition was absent in the spring season during low abundance periods. These samples were taken prior to the establishment of the closed areas so fishing pressure was equal everywhere (or proportional to local population density), and the habitat was altered by commercial fishing activity. Density-dependent habitat use is in effect during these low abundance periods as evidenced by the fact that there is spatial heterogeneity in abundance (Fig. 5), but not in condition (Table 4). Note that even prior to the closures, population density was higher in Stratum 1160 than on the rest of Georges Bank (Fig. 5). Condition may have been particularly homogenous over locations in the spring because this is a spring-spawning species. As much as $20 \%$ of female body mass is contained in the ovaries (Wilk et al. 1990). The higher energy demands, coupled with the fact that the fish occupy the same area as in the fall when energy demands are lower, may have depleted local resources resulting in a density-dependent response. When populations were high in the spring, the population occupied a larger area (and presumably more habitats), resulting in the spatial heterogeneity in fitness (the site-dependent response) that we observed. In the fall, energy needs are lower, food may be more abundant, competition is less, and fish may occupy a wider range of habitats (i.e. may have begun their fall migration). Site dependence results in the spatial heterogeneity in condition that we see.

The spatial heterogeneity in fitness we found is consistent with previous work by Link et al. (2005). They found 2 different habitats within CAII, a low energy sand habitat and a high energy sand habitat. Yellowtail flounder were larger inside the closed area when compared to those sampled outside it, and were also larger in the low energy habitat when compared to the high energy habitat within CAII (Link et al. 2005). Link et al. (2005) also showed that the low energy habitat contained greater abundance and diversity of benthic invertebrates than the high energy habitat. This would seem to indicate higher food availability since yellowtail flounder eat primarily polychaetes and small crustaceans (Langton 1983, Link et al. 2002). These habitats appear to continue into $5 \mathrm{Z}$, the closed area on the Canadian side of the border (Kostylev et al. 2005). Link et al. (2005) did not find greater abundances of yellowtail flounder inside the closed area, but they only sampled 3 nautical miles outside CAII, well within known migratory distances for yellowtail flounder (Stone \& Nelson 2003) and consistent with spillover effects of adult fishes observed from areas closed to fishing (Murawski et al. 2005).

Our results here support the BM, which is a model driven by density dependence. We do, however, see evidence of site dependence (the driving force behind the other 2 models of habitat use) in the spatial heterogeneity of condition indices we detected in 
our geospatial analysis. Rodenhouse et al. (1997) has suggested that site dependence is not necessarily an exclusive alternative to density dependence; the 2 responses may work in concert. Fish in preferred habitat may show a site-dependent response until population levels reach the point where density dependence begins to act.

The geospatial approach we used here has applications in fisheries management. Using basic data routinely collected during resource assessment surveys, such as capture location, length, weight, and abundance, we were able to identify an important yellowtail flounder population center, demonstrate that fish may use habitat in both site-dependent and densitydependent ways, and determine the area over which those forces were operating. We also demonstrated a seasonal component in their distribution and that there was a transition in habitats within the closed areas confirming earlier work by Link et al. (2005). Bottom depth, water temperatures, and salinities, oceanographic conditions commonly used to describe large-scale habitat attributes, provided additional information to refine the model. These types of data could be used in the future to determine sites for additional closed areas or to test the efficacy of areas which are already closed.

Acknowledgements. We thank William Kramer of the National Marine Fisheries Service laboratory in Woods Hole, Massachusetts, for providing the data used in this study from the trawl survey database. We also thank Dr. Daniel Civco for helping solve projection problems in ArcGIS. We thank Dr. Peter Turchin, Dr. Robert Colwell, and Dr. Frederick Thurberg for helpful suggestions, both statistical and grammatical, in the preparation of this manuscript. Peter J. Auster was supported by the National Marine Sanctuary Foundation and NOAA's Office of National Marine Sanctuaries. The opinions expressed herein are those of the authors and do not necessarily reflect the opinions of NOAA or its subagencies.

\section{LITERATURE CITED}

Abrams PA (2000) The impact of habitat selection on the spatial heterogeneity of resources in varying environments. Ecology 81:2902-2913

Almeida F, Valentine P, Reid R, Arlen L and others (2005) The effectiveness of marine protected areas on fish and benthic fauna: the Georges Bank closed area II example. Am Fish Soc Symp 41:589-590

Asch RG, Collie JS (2008) Changes in a benthic megafaunal community due to disturbance from bottom fishing and the establishment of a fishery closure. Fish Bull 106: 438-456

Auster PJ, Langton RW (1999) The effects of fishing on fish habitat. Am Fish Soc Symp 22:150-187

Auster PJ, Malatesta RJ, Langton RW, Watling L and others (1996) The impacts of mobile fishing gear on seafloor habitats in the Gulf of Maine (Northwest Atlantic): implications for conservation of fish populations. Rev Fish Sci $4: 185-202$

> Auster PJ, Joy K, Valentine PC (2001) Fish species and community distributions as proxies for seafloor habitat distributions: the Stellwagen Bank National Marine Sanctuary example (Northwest Atlantic, Gulf of Maine). Environ Biol Fishes 60:331-346

Azarovitz T (1981) A brief historical review of the Woods Hole Laboratory trawl survey time series. Publ Spec Can Sci Halieut Aquat 58:62-67

> Barange M, Coetzee J, Takasuka A, Hill K and others (2009) Habitat expansion and contraction in anchovy and sardine populations. Prog Oceanogr 83:251-260

> Brodie WB, Walsh SJ, Atkinson DB (1998) The effect of stock abundance on range contraction of yellowtail flounder (Pleuronectes ferruginea) on the Grand Bank of Newfoundland in the Northwest Atlantic from 1975 to 1995. J Sea Res 39:139-152

> Brodziak J, Legault CM (2005) Model averaging to estimate rebuilding targets for overfished stocks. Can J Fish Aquat Sci 62:544-562

$>$ Burton MPM (1994) A critical period for nutritional control of early gametogenesis in female winter flounder, Pleuronectes americanus (Pisces: Teleostei). J Zool (Lond) 233:405-415

> Burton MP, Idler DR (1984) The reproductive cycle in winter flounder, Pseudopleuronectes americanus (Walbaum). Can J Zool 62:2563-2567

> Cushing DH (1973) Dependence of recruitment on parent stock. J Fish Res Board Can 30:1965-1976

> Delibes M, Gaona P, Ferreras P (2001) Effects of an attractive sink leading into maladaptive habitat selection. Am Nat 158:277-285

> Essington TE, Kitchell JF (1999) New perspectives in the analysis of fish distributions: a case study on the spatial distribution of largemouth bass (Micropterus salmoides). Can J Fish Aquat Sci 56:52-60

Fretwell SD, Lucas HL Jr (1969) On territorial behavior and other factors influencing habitat distribution in birds. I. Theoretical development. Acta Biotheor 19:16-36

> Grand TC, Grant JWA (1994) Spatial predictability of resources and the ideal free distribution in convict cichlids, Cichlasoma nigrofasciatum. Anim Behav 48: 909-919

Grosslein M (1969) Groundfish survey program of BCF Woods Hole. Commer Fish Rev 31:22-30

Hilborn R, Walters CJ (1992) Quantitiative fisheries stock assessment: choice dynamics and uncertainty. Chapman \& Hall, New York, NY

Houghton RG (1987) The consistency of the spatial distributions of young gadoids with time. ICES CM1987/D:15: $1-7$

Iles TD, Sinclair M (1982) Atlantic herring: stock discreteness and abundance. Science 215:627-633

> Jakob EM, Marshall SD, Uetz GW (1996) Estimating fitness: a comparison of body condition indices. Oikos 77:61-67

Johnson D, Morse W, Berrien P, Vitaliano J (1999) Essential fish habitat source document: yellowtail flounder, Limanda ferruginea, life history and habitat characteristics. NOAA Tech Mem 140:1- 29

Kaiser MJ, Clarke KR, Hinz H, Austen MCV, Somerfield PJ, Karakassis I (2006) Global analysis of response and recovery of benthic biota to fishing. Mar Ecol Prog Ser $311: 1-14$ 
Knight TW, Morris DW (1996) How many habitats do landscapes contain? Ecology 77:1756-1764

Kostylev VE, Todd BJ, Longva O, Valentine PC (2005) Characterization of benthic habitat on northeastern Georges Bank, Canada. Am Fish Soc Symp 41:141-152

Kristan III WB (2003) The role of habitat selection behavior in population dynamics: source-sink systems and ecological traps. Oikos 103:457-468

Langton RW (1983) Food habitats of yellowtail flounder, Limanda ferruginea (Storer), from off the northeastern United States. Fish Bull 81:15-22

Le Cren E (1951) The length-weight relationship and seasonal cycle in gonad weight and condition in the perch (Perca fluviatilis). J Anim Ecol 20:201-219

Levin PS (1994) Fine-scale temporal variation in recruitment of a temperate demersal fish: the importance of settlement versus post-settlement loss. Oecologia 97:124-133

Lindholm J, Auster P, Valentine P (2004) Role of a large marine protected area for conserving landscape attributes of sand habitats on Georges Bank (NW Atlantic). Mar Ecol Prog Ser 269:61-68

Link JS, Bolles K, Milliken CG (2002) The feeding ecology of flatfish in the Northwest Atlantic. J Northwest Atl Fish Sci 30:1-17

Link J, Almeida F, Valentine P, Auster P, Reid R, Vitaliano J (2005) The effects of area closures on Georges Bank. Am Fish Soc Symp 41:345-368

MacCall AD (1990) Dynamic geography of marine fish populations. University of Washington Press, Seattle, WA

McPeek MA, Rodenhouse NL, Holmes RT, Sherry TW (2001) A general model of site-dependent population regulation: population-level regulation without individual-level interactions. Oikos 94:417-424

Morse WW (1979) An analysis of maturity observations of 12 groundfish species collected from Cape Hatteras, North Carolina to Nova Scotia in 1977. Sandy Hook Lab Rep, SHL 79-32, National Marine Fisheries Service, Silver Spring, MD

Murawski SA, Wigley SE, Fogarty MJ, Rago PJ, Mountain DG (2005) Effort distribution and catch patterns adjacent to temperate MPAs. ICES J Mar Sci 62:1150-1167

Myers RA, Stokes K (1989) Density-dependent habitat utilization of groundfish and the improvement of research surveys. ICES CM1989/D:15:1-17

NEFSC (Northeast Fisheries Science Center) (2008) Assessment of 19 northeast groundfish stocks through 2007. Report of the 3rd Groundfish Assessment Review Meet- ing (GARM III). Northeast Fish Sci Cent Ref Doc 08-15, NEFSC, Woods Hole, MA

Petitgas P (1998) Biomass-dependent dynamics of fish spatial distributions characterized by geostatistical aggregation curves. ICES J Mar Sci 55:443-453

Pittman SJ, McAlpine CA (2003) Movements of marine fish and decapod crustaceans: process, theory and application. Adv Mar Biol 44:205-294

Pulliam HR (1988) Sources, sinks, and population regulation. Am Nat 132:652-661

Pulliam HR, Danielson BJ (1991) Sources, sinks, and habitat selection: a landscape perspective on population dynamics. Am Nat 137:S50-S66

Reid RN, Almeida FP, Zetlin CA (1999) Fishery-independent surveys, data sources, and methods. NOAA Tech Mem 122:1-39

Rodenhouse NL, Sherry TW, Holmes RT (1997) Site-dependent regulation of population size: a new synthesis. Ecology 78:2025-2042

Ryan TP (1997) Modern regression methods. Wiley, New York, NY

Schultz ET, Ludwig M (2005) The essentials on estuarine fish habitat, its evaluation and protection by federal fisheries law. In: Visgilio G, Whitelaw DM (eds) Our changing coast: private rights and public trust. Edward Elgar Publishing Inc., Northampton, MA, p 148-167

Shepherd JG (1982) A versatile new stock-recruitment relationship for fisheries, and the construction of sustainable yield curves. ICES J Mar Sci 40:67-75

Shepherd TD, Litvak MK (2004) Density-dependent habitat selection and the ideal free distribution in marine fish spatial dynamics: considerations and cautions. Fish Fish 5:141-152

Simpson MR, Walsh SJ (2004) Changes in the spatial structure of Grand Bank yellowtail flounder: testing MacCall's basin hypothesis. J Sea Res 51:199-210

Smith RL, Smith TM (1998) Elements of ecology, 4th edn. Addison Wesley Longman, New York, NY

Stone HH, Nelson CW (2003) Tagging studies on eastern Georges Bank yellowtail flounder. Research Document 2003/056, Department of Fisheries and Oceans, Ottawa

Webster R, Oliver M (2001) Geostatistics for environmental scientists. John Wiley \& Sons, New York, NY

Wilk SJ, Morse WW, Stehlik LL (1990) Annual cycles of gonad-somatic indices as indicators of spawning activity for selected species of finfish collected from the New York Bight. Fish Bull 88:775-786 
Appendix 1. Geospatial modeling of condition

Kriging or cokriging was used to construct a surface representing the spatial variation in condition. Kriging is an interpolation method used to create a prediction surface from a 2-dimensional array of point data. Cokriging uses additional information (water depth, bottom temperature, surface temperature, or bottom salinity at those points in this case) to improve the accuracy of the prediction surface. Data from nearby points are more heavily weighted in the interpolation than data from those farther away. Weighting factors for kriging come from a semivariogram. The semivariogram is a plot of the semivariance (one-half the squared difference between 2 condition values, a measure of similarity) and the geographic distance between the 2 points. If spatial autocorrelation exists, the plot will rise and then level off at some distance where the relationship no longer holds (Fig. A1). If no spatial autocorrelation exists, the plot will be a flat, horizontal line. The parameters of a line, fit through the empirical semivariogram, provide the weighting factors. The range is the distance over which autocorrelation exists. I have called this the autocorrelation distance (ACD) throughout the text so as not to confuse it with the geographical range occupied by the population. The sill represents the greatest difference between 2 points where autocorrelation still exists.

To construct the semivariogram, we had to apply a small amount of random variation to the catch location for each fish. Originally all of the fish captured in a trawl were assigned to a single point (i.e. the starting point of the trawl). The ArcGIS ${ }^{\circledR}$ Geostatistical Analyst extension (ArcGIS ${ }^{\circledR}$, ESRI Corporation) requires input of the mean, or the minimum or maximum value when analyzing multiple samples assigned to the same location. Since these values would be binned (averaged over a distance or lag) later in the construction of the semivariogram, the loss of

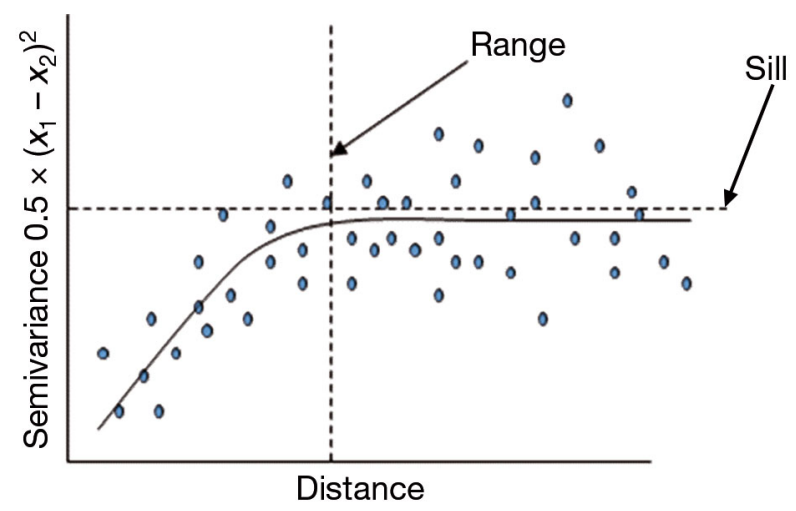

Fig. A1. A generalized semivariogram showing evidence of spatial autocorrelation and the location of the range (autocorrelation distance) and the sill variation at this stage could have made it less likely to detect spatial heterogeneity in our proxy for fitness, biasing the analysis. We modified the latitude of each coincident sample slightly such that individual fish were 'shifted' up to $555 \mathrm{~m}$, less that the length of the trawl track and well within the 20 to $40 \mathrm{~km}$ bin used in fitting the semivariogram. Once the coincident samples had been separated, the data were detrended if necessary and kriging or cokriging was used to create a predictive surface of log mass residuals.

Kriging requires fitting one of several parametric semivariance models to the sample semivariogram. The stable model was used for all semivariograms except for 1 instance where the spherical model gave a slightly better result. The stable model is:

$$
\gamma(h ; \theta)=\theta_{\mathrm{s}}\left[1-\exp \left(-3\left(\frac{\|h\|}{\theta_{\mathrm{r}}}\right)^{\theta_{\mathrm{e}}}\right)\right]
$$

where $\theta_{\mathrm{s}} \geq 0$ and $\theta_{\mathrm{e}} \leq 2$ and $h$ is the lag size, $\theta_{\mathrm{s}}$ is the sill parameter, $\theta_{\mathrm{r}}$ is the ACD parameter and $\theta_{\mathrm{e}}$ is the shape parameter which varies between 0 and 2 and controls the curvature of the line representing the fitted semivariogram. The spherical model is:

$$
\gamma(h ; \theta)=\left\{\begin{array}{cc}
\theta_{\mathrm{r}}\left[\frac{3}{2} \frac{\|h\|}{\theta_{\mathrm{r}}}-\frac{1}{2}\left(\frac{\|h\|}{\theta_{\mathrm{r}}}\right)^{3}\right] & \text { for } 0 \leq\|h\| \leq \theta_{\mathrm{r}} \\
\theta_{\mathrm{s}} & \text { for } \theta_{\mathrm{r}}<\|h\|
\end{array}\right.
$$

where $h$ is the lag size, $\theta_{\mathrm{s}} \geq 0$ is the partial sill parameter and $\theta_{\mathrm{r}} \geq 0$ is the ACD parameter.

We inferred the significance of the spatial variability in condition with a cross-validation procedure. In the crossvalidation procedure, each observed value for condition is regressed against an expected value $\hat{\mathrm{k}}$ that is generated by kriging the dataset without that observed value. In such analyses, eliminating extreme values that may be produced by kriging and would have undue leverage on the regression is recommended (Webster \& Oliver 2001). We used robust regression, which iteratively removes extreme values. Values $>2$ standard deviations from the regression line were removed, and a new regression was carried out on the remaining data (Ryan 1997). The process continued until there were no more outliers or until the next iteration resulted in cumulative elimination of $>10 \%$ of the data. The outliers produced by this procedure were plotted in ArcGIS ${ }^{\circledR}$ to seek patterns in their geographical location. A $t$-test was used to compare depth, water temperature, and salinity in areas containing outliers versus those areas that did not to determine if these factors were related to the extremes in condition index detected by the robust regression. After removal of outliers, a significant regression slope was taken as evidence of spatial autocorrelation. The correlation coefficient $R^{2}$ measures the strength of the relationship. 